Chapter 10

\title{
Surface Proteins of Staphylococcus aureus
}

\author{
Janet Jan-Roblero, Elizabeth García-Gómez, \\ Sandra Rodríguez-Martínez, \\ Mario E. Cancino-Diaz and Juan C. Cancino-Diaz
}

Additional information is available at the end of the chapter

http://dx.doi.org/10.5772/65976

\begin{abstract}
Staphylococcus aureus is a commensal bacterium that causes infections such as sepsis, endocarditis, and pneumonia. S. aureus can express a variety of virulence factors, including surface proteins. Surface proteins are characterized by presence of a Sec-dependent signal sequence at the amino terminal, and the sorting signal domain. Surface proteins are covalently attached to peptidoglycan and they are commonly known as cell wallanchored (CWA) proteins. CWA proteins have many functions and participate in the pathogenesis of $S$. aureus. Furthermore, these proteins have been proposed as therapeutic targets for the generation of vaccines. In this chapter, different topics related to CWA proteins of $S$. aureus are addressed. The molecular structure of CWA proteins and their role as virulence factors of $S$. aureus are described. Furthermore, the involvement of CWA proteins in the processes of adhesion, invasion of host cells and tissues, evasion of the immune response, and the formation of biofilm is discussed. In addition, the role of CWA proteins in skin infection and the proposal to use them as potential vaccine antigens are described. The information contained in this chapter will help the readers to understand the biology of CWA proteins and to recognize the importance of surface molecules of $S$. aureus.
\end{abstract}

Keywords: Staphylococcus aureus, CWA proteins, surface proteins, vaccines, skin

\section{Introduction}

Staphylococcus aureus has been widely studied due to their ability to cause infections such as sepsis, endocarditis, and pneumonia. Therefore, it is relevant to find new therapeutic targets against this bacterium; since the treatments with common antibiotics are seldom effective due to the acquisition for multidrug resistance, such as methicillin-resistant S. aureus (MRSA) 
strains [1, 2]. S. aureus expresses a variety of virulence factors and some of them are found in the bacterial surface (surface proteins). The surface proteins of $S$. aureus are covalently attached to the peptidoglycan, and for that reason, they are named as cell wall-anchored (CWA) proteins. Within the genus Staphylococcus, S. aureus has an average of 24 different CWA proteins, whereas Staphylococcus epidermidis and Staphylococcus lugdenensis have less CWA proteins. Not all strains of $S$. aureus have the same 24 CWA proteins on their surfaces, there are differences according with their genotypes. With regard to the expression of CWA proteins, it is dependent on the bacterial growth phase and growth conditions; for example, some proteins are expressed only under limited iron concentration $[3,4]$, while others are expressed predominantly in the exponential phase [5], or in the stationary phase of bacterial growth [6]. The CWA proteins are classified into four families according to a structure-function analysis and to their different motifs. Currently, the CWA proteins have taken great interest due to their multiple functions during the pathogenesis of S. aureus.

\section{Structure of CWA proteins}

All CWA proteins contain a Sec-dependent signal sequence at the amino terminal and at the carboxyl terminal a sorting signal and a hydrophobic domain (wall-spanning W). The sorting signal domain contains the characteristic motif for breaking by the sortase LPXTG (LeuPro-X-Thr-Gly; wherein $X$ represents any amino acid). The hydrophobic domain retains the protein in the bacterial membrane during secretion, so that the sortase can join and carry out its transpeptidase function. Between the amino and carboxyl terminal domains, there are different regions or functional domains. Based on its molecular structure and arrangement, the CWA proteins of S. aureus have been classified into four families: the MSCRAMM family, the NEAT motif family, the three-helical bundle family, and the G5-E repeat family (Table 1).

\subsection{The MSCRAMM family}

The main feature of this family of proteins is its structural similarity and its mechanism for binding the ligand. The general structure of these proteins is a domain $\mathrm{A}$ at the amino terminal and a region R. The A domain is divided into subdomains: NI, N2, and N3, which integrate the ligand-binding domain. The N2 and N3 subdomains form folding structures IgG-like [7] that are important to form the ligand-binding site. With respect to ligand-binding mechanism of these proteins, they bind to fibrinogen through the mechanism "dock, lock, and latch" (DLLs) by N2 and N3 subdomains. The DLL mechanism occurs when the ligand dock to the open apo form and conformation changes create a closed form, in which the ligands are locked into a place [8]. Clumping factor A (ClfA) and ClfB proteins of S. aureus and serine-aspartate repeat-containing protein $\mathrm{G}(\mathrm{SdrG})$ of $S$. epidermidis are representative proteins of this family.

The R region of the Sdr- and Clf proteins is composed by repeated Ser-As, known as the SD region. However in the fibronectin-binding protein A (FnBPA) or (FnBPB), the R region contains repeated fibronectin-binding, which have the function of mediating ligand binding. The $\mathrm{SdrC}, \mathrm{SdrD}, \mathrm{SdrE}$, and bone sialo-binding protein (BBP) proteins, which are MSCRAMM of $S$. aureus, have two or more repeated subdomains named as $\mathrm{B}_{\mathrm{SDR}^{\prime}}$ ranging from 110 to 113 amino 


\begin{tabular}{|c|c|c|c|}
\hline Protein family & Structural motifs and domains ${ }^{*}$ & Proteins & Function during infection \\
\hline \multirow{4}{*}{$\begin{array}{l}\text { (1) MSCRAMM } \\
\text { Clf-Sdr }\end{array}$} & \multirow{4}{*}{$\begin{array}{l}\text { N-terminal A region (comprises } \\
\text { subdomains } \mathrm{N} 1, \mathrm{~N} 2, \mathrm{~N} 3 \text { ); } \mathrm{B}_{\mathrm{SDR}} \text { repeats } \\
\text { (in } \mathrm{SdrC}, \mathrm{SdrD} \text { and } \mathrm{SdrE} \text { ); } \mathrm{R} \text { region } \\
\text { (known as } \mathrm{SD} \text { region, contains serine- } \\
\text { aspartate repeats) }\end{array}$} & $\mathrm{ClfA}^{\mathrm{a}}$ & $\begin{array}{l}\text { Adhesion to fibrinogen; degradation of } \\
\mathrm{C} 3 \mathrm{~b} \text {. Immune evasion }\end{array}$ \\
\hline & & ClfB & $\begin{array}{l}\text { Fibrinogen, keratin and loricrin } \\
\text { binding. Nasal colonization by adhesion } \\
\text { to desquamated epithelial cells }\end{array}$ \\
\hline & & SdrC & $\begin{array}{l}\beta \text {-Neurexin binding. Adhesion to } \\
\text { desquamated nasal epithelial cells }\end{array}$ \\
\hline & & SrdD & $\begin{array}{l}\text { Adhesion to desquamated nasal } \\
\text { epithelial cells }\end{array}$ \\
\hline \multirow[t]{2}{*}{ FnBp } & \multirow[t]{2}{*}{$\begin{array}{l}\text { A region (subdomains N1, N2, N3); R } \\
\text { region (contains fibronectin-binding } \\
\text { repeats) }\end{array}$} & FnBpA & $\begin{array}{l}\text { Fibrinogen, fibronectin and elastin } \\
\text { binding. Adhesion to extracellular } \\
\text { matrix; cell host invasion. }\end{array}$ \\
\hline & & $\mathrm{FnBpB}$ & $\begin{array}{l}\text { Fibronectin-binding. Adhesion to } \\
\text { extracellular matrix; cell host invasion }\end{array}$ \\
\hline Cna & $\begin{array}{l}\text { A region (subdomains N1, N2, N3); } \\
B_{\mathrm{CNA}} \text { repeats }\end{array}$ & Cna & $\begin{array}{l}\text { Collagen binding. Adhesion to } \\
\text { extracellular matrix }\end{array}$ \\
\hline \multirow[t]{3}{*}{ (2) NEAT } & \multirow[t]{3}{*}{$\begin{array}{l}\text { Near iron transporter motif; C-terminal } \\
\text { hydrophilic stretch (in IsdA) }\end{array}$} & IsdA & $\begin{array}{l}\text { Heme, fibrinogen, fibronectin, } \\
\text { cytokeratin and loricrin binding. } \\
\text { Heme capture and iron uptake; nasal } \\
\text { colonization }\end{array}$ \\
\hline & & IsdB $^{a}$ & $\begin{array}{l}\text { Heme, hemoglobin and } 3 \beta \text { integrins } \\
\text { binding. Heme capture and iron uptake; } \\
\text { invasion of non-phagocytic cells }\end{array}$ \\
\hline & & IsdH & $\begin{array}{l}\text { Heme, hemoglobin binding. Heme } \\
\text { capture and iron acquisition; immune } \\
\text { evasion by C3b degradation }\end{array}$ \\
\hline $\begin{array}{l}\text { (3) Three helical } \\
\text { bundle }\end{array}$ & $\begin{array}{l}\text { Tandemly linked triple-helical bundle } \\
\text { domains (known as EABCD); } \\
\text { repeat-containing Xr region; } \\
\text { nonrepetitive Xc region }\end{array}$ & Protein A & $\begin{array}{l}\text { IgG, IgM and TNRF1 binding. Evasion } \\
\text { of immunity; increased inflammation } \\
\text { during pneumonia and skin infection }\end{array}$ \\
\hline (4) G5-E & $\begin{array}{l}\text { A region; alternating repeats of G5 } \\
\text { and } \mathrm{E} \text { domains }\end{array}$ & SasG & $\begin{array}{l}\text { Adhesion to desquamated epithelial } \\
\text { cells; formation of biofilm }\end{array}$ \\
\hline
\end{tabular}

Table 1. Structure-function of CWA proteins.

acids and that are located between the region $\mathrm{A}$ and the $\mathrm{SD}$ region. The repeated $\mathrm{B}_{\mathrm{SDR}}$ are folded separately and form a rigid bar and it is $\mathrm{Ca}^{2+}$ dependent for structural integrity $[9,10]$.

An atypical MSCRAMM protein is collagen adhesin (Cna). This protein binds to collagen, also has a domain $\mathrm{A}$ in its N-terminal and it is divided into three subdomains N1, N2, and N3. The Cna differs from the other members MSCRAMMs because its ligand-binding domain (IgG-folded) is composed of the N1 and N2 subdomains, and not composed of the N2 and N3 
subdomains as other MSCRAMMs typical. Furthermore, the space between domain A and the cell wall-spanning $\mathrm{W}$ domain consists of a variable number of repeated $\mathrm{B}_{\mathrm{CNA}}$ domains, which are different from $\mathrm{B}_{\mathrm{SDR}}$ subdomains. Another difference is that the Cna has a different ligand-binding mechanism named as collagen hug.

\subsection{NEAT motif family}

The main feature of this family is the presence of near iron transporter (NEAT) motifs, which recognize and bind to heme or hemoglobin. Proteins iron-regulated surface (Isd) A, B, and H contain NEAT motif (one NEAT motif for IsdA, two NEAT motif for IsdB, and three NEAT motif for IsdH) and these proteins are involved in the capture of heme from the hemoglobin. Isd is important for the survival of the bacterium into the host, where the iron is limited. Besides, Isd is involved actively in the metabolism of heme. Heme binds to Isd, and then heme binds to a membrane transporter protein, which transfers heme into the cytoplasm. In the cytoplasm, the iron is released from heme by hemoxygenases [4, 11]. The structure of the NEAT domain has been elucidated and the molecular mechanism of ligand-binding was determined [12]. Other Isd proteins can bind different ligands to the heme group, as the case IsdA that binds to fibrinogen, fibronectin, cytokeratin 10, and loricrin; and IsdB that binds to $3 \beta$ integrins.

\subsection{Three-helical bundle family}

The main feature of this family is the presence of several single separately-folded three-helical bundles. Protein A of S. aureus is the common prototype of this family. Protein A has five homologous modules in its amino terminal, known as EABCD (each module has a folding three -helical bundles) which can bind to different ligands; then there is a $\mathrm{Xr}$ region composed by repeated octapeptides, which are highly variable number, and finally in the constant $\mathrm{Xc}_{\mathrm{c}}$ region $[13,14]$. Protein A is a multifunctional CWA protein ubiquitous in S. aureus and frequently it is used to subtype strains, based on the variation of the DNA sequence-encoding $\mathrm{Xr}$.

Other proteins of S. aureus containing three-helix bundles are: the binder protein IgG (Sbi) with four three-helix bundles which is not covalently linked to the cell wall $[15,16]$, and the proteins that have a single three-helix bundle, the staphylococcal complement inhibitor (SCIN) and the extracellular fibrinogen binding protein (Efb) [17], which are involved in the immune evasion.

\subsection{The G5-E repeat family}

The basic structure of this family is G5-E repeat domain. Each domain G5 has five conserved glycine residues, which adopt a folding of $\beta$-triple helix- $\beta$-like structure. Currently, it is unknown whether this domain is involved in the ligand-binding function. The region $\mathrm{E}$ is known as the spacer region and is composed of a sequence of 50 amino acid residues [18, 19]. The domain G5 and the region E form the structure of this family. The G5-E unit is repeated in a tandem arrangement. In addition, proteins of this family have a domain $\mathrm{A}$ in the amino terminal. The surface protein $G$ (SasG) of $S$. aureus and the accumulation-associated protein (Aap) of S. epidermidis are closely homologous and are members of this family; both proteins 
are involved in biofilm formation. The G5-E repeated of Aap and SasG are exposed on the surface of the bacterium. For both proteins become functional that must be processed; in the case of Aap, the domain A of the amino terminal is removed by proteolytic processing and in the case of SasG occurs by limited breaking within G5-E domains [20].

\subsection{Other CWA protein families}

There are other CWA proteins with different functional domains such as the legume lectin and the nucleotidase. These two groups of CWA proteins are classified outside the four families mentioned above, because they are not exclusive of $S$. aureus. CWA proteins with a legume lectin domain are represented by the serine-rich adhesion of platelet SraP [21]. SraP is composed of a BR region and a short serine-rich region (SSR1). The BR region is formed of three different structural domains: the legume lectin-like, the $\beta$-grasp fold ( $\beta$-GF) and the cadherinlike (CHLD). It has been observed that the function of the BR region is to recognize Neu5Accontaining glycoproteins of mammalian cells; such as the salivary glycoprotein gp340 [22]. In addition, the SraP is involved in bacterial adhesion and the invasion of mammalian cells. On the other hand, the nucleotidase domain has been identified in CWA protein SasH of $S$. aureus. The nucleotidase motif is enzymatically active and contributes to evade the host immune response $[23,24]$. It has been shown that when S. aureus is phagocytosed, the SasH (also named as synthase adenosine, AdsA) dephosphorylates intracellular ATP to adenosine, where the adenosine is immunoregulatory because the adenosine inhibits the oxidative burst and promotes the survival of $S$. aureus within neutrophil $[25,26]$.

\section{Posttranslational modifications of CWA proteins}

The MSCRAMMs proteins achieve proteolytic posttranslational modification in the domain A. Proteases that remove subdomain N1 of MSCRAMMs are located on the bacterial cell surface. Proteolytic processing is conducted by a staphylococcal protease, called aureolysin, which cleaves between the subdomains N1 and N2 of ClfB and ClfA. For FnBPA, there is not a staphylococcal protease, the responsible of this processing is the thrombin of the host. Removal of N1 of ClfB can decrease the length of the protein and cause lack of binding fibrinogen [5]. It is thought that the elimination of $\mathrm{N} 1$ subdomain reduces the ability of $S$. aureus to adhere to fibrinogen, loricrin, and cytokeratin 10. The biological importance of the elimination of the subdomain N1 of ClfA and FnBPA is unclear, since experiments suggest no reducing biofilm formation by FnBPA; or no decrease in adhesion to fibrinogen by ClfA and FnBPA processed proteolytically $[27,28]$. However, it has been reported that under certain conditions, FnBPs are degraded by the S. aureus V8 protease, reducing the ability of the bacterium to adhere to fibronectin [29].

Another posttranslational modification is the glycosylation of proteins Clf-Sdr. It has been shown that the glycosyltransferases $\mathrm{SdgB}$ and $\mathrm{SdgA}$ of $S$. aureus are responsible to modify the SD region of the Clf-Sdr family. This modification involves adding N-acetylglucosamine residues in the region SD protecting it from the degradation by neutrophil serine protease, cathepsin G [30]. Thus, the glycosylation of repeated SD is crucial for functional maintenance of MSCRAMMs on the surface of S. aureus. 


\section{CWA proteins as virulence factors}

The generation of mutants is a useful tool to know the function of a gene; however, the study of CWA proteins has been complicated because the generation of defective mutants of CWA protein had generated, in some cases, unexpected results due to functional redundancy. For example, S. aureus expresses some CWA proteins that bind to fibrinogen, and most of the strains can produce two proteins with the same function; in consequence, a mutant protein could be replaced by a protein with the correct function. Another difficulty that occurs in the study of CWA proteins is to obtain mutants in the isolates of clinical relevance, since the studies have been conducted with laboratory strains; such as S. aureus Newman and derivatives of NCTC8325 strains. Finally, there is the problem of species because some CWA proteins have a specific function in mice but in humans have different functions or behavior [31].

Despite the difficulties mentioned above, the role of CWA proteins in virulence has been studied. Human population (20\%) is permanently colonized by S. aureus in the nasal cavity [32], where the bacterium is able to grow exponentially and to express high levels of mRNA encoding CWA proteins [33]. ClfB [34] and IsdA [35] contribute in the nasal colonization in rodents, and ClfB also in humans [36]. ClfB is capable of binding to keratin 10 of mouse and human [37]. Keratin 10 is the largest component of squamous cells. ClfB also binds to the loricrin protein [38]. Some other CWA proteins (such as SdrC, SdrD, SasG, and SasX) can promote adhesion to squamous cells but the ligand or ligands involved are not known [39-42].

\subsection{CWA proteins in the invasion of epithelial and endothelial cells}

Recently, S. aureus was recognized as an intracellular pathogen and its ability to survive inside neutrophils. S. aureus can be taken directly by nonphagocytic cells and host cells; subsequently, it can cause damage to the above mentioned cells by the production of cytotoxins. In addition, intracellular bacterium is protected against the attack by the host because $S$. aureus acquires a state of semidormancy known as small colony variants, which yields intrinsic resistance to antibiotic therapy [43].

In the case of FnBPA and FnBPB proteins, the binding of these proteins to fibronectin facilitates S. aureus internalization [44-46]. Fibronectin is composed of three different types of structural modules, called 1,2 , and 3 , of which the modules type 1 contain two $\beta$ sheets involved in interactions with the binding domains of FnBPs [47]. In addition, an arginine-glycine-aspartate sequence of one of the modules type 3 of fibronectin is recognized by integrins. Particularly, the interactions of fibronectin with FnBPs and integrin $\alpha 5 \beta 1$ initiate the activation of a signaling cascade that triggers a cytoskeletal rearrangement in the host cell, which causes endocytosis of S. aureus [48].

\subsection{Immune system and inflammation}

The CWA proteins are involved in immune evasion. Protein A binds to the Fc region of IgG, this binding leads to an incorrect orientation of IgG antibody, preventing the recognition of the bacterium by neutrophils and the activation of the classical complement pathway [49]. 
Furthermore, it has been demonstrated that in pulmonary epithelial cells, protein A is capable of interacting with tumor necrosis factor receptor 1 (TNFR1), triggering the production of interleukin-8 (IL-8) and the neutrophil recruitment, promoting inflammation and tissue damage [50]. Also it has been reported the involvement of protein $\mathrm{A}$ in the production of interferon $\beta$ (IFN $\beta$ ) and IL-6 in a mouse pneumonia model [51].

ClfA and Can are involved in evading the immune system by recruiting regulators of complement pathway [52]. Furthermore, ClfA is involved in bacterial survival by binding to fibrinogen, because in a sepsis model this interaction reduces the probability of $S$. aureus to be eliminated by neutrophils [53]. It has also demonstrated the importance of modifying ClfA by glycosyltransferases, which add $\mathrm{N}$-acetylglucosamine to the SD region, thereby preventing the proteolysis by cathepsin-B from human neutrophils [30].

\subsection{Biofilms}

One of the major virulence factors of S. aureus is its ability to form biofilms on implanted medical devices, which favors resistance to antibiotics, survival, and dissemination [31]. In the formation of biofilms, a polysaccharide matrix is involved, particularly the molecule poly-Nacetylglucosamine (PNAG) or also called adhesin intercellular polysaccharide (PIA), whose production depends on the proteins encoded by the operon icaADBC (intracellular adhesion) $[54,55]$. Furthermore, the CWA proteins of the cell-wall are also involved in biofilm formation, such as Bap, ClfB, FnBPs, SasC, SasG, and protein A [31]. It has been shown that Bap and Sas $C$ are involved in adhesion of $S$. aureus to polystyrene surfaces and the bacterial accumulation in biofilm formation [56, 57]. In the case of FnBPs, it has been proposed that N2 and N3 subdomains of the domain A are required to promote the bacterial accumulation in biofilm formation [27]. The mechanism of biofilm formation involving SasG consists of an array of loop structures, which are capable of interacting with other SasG located on the surface of another bacterium, thus allowing the accumulation of S. aureus [18].

\section{Involvement of CWA proteins in skin infections}

The study of the participation of CWA proteins in skin infections and abscess formation has been achieved mainly in animal models with CWA protein mutant strains of S. aureus (Table 2). S. aureus strains deficient in sortase proteins, which lost all CWA proteins, are unable to form abscess in mice [58,59]. Mice inoculated with $S$. aureus strain Newman, deficient in ClfA, showed a lower bacterial load in skin abscesses compared with the wild-type strain [60]. The ClfA protects the bacterium from phagocytosis by neutrophils because ClfA recruits fibrinogen to the surface of the bacterium, thereby preventing the opsonization and recognition by receptors of phagocytic cells.

In a murine skin abscess model, infected with S. aureus LS-1 strain, mutant in FnBPA and FnBPB, the bacterial load decreased [60]. FnBPs is also able to adhere and invade the skin keratinocytes [61], thus contributing to the development of skin infection. SasX contributes to skin infection, which was demonstrated in a murine skin infection model in challenge with a SasX-deficient 


\begin{tabular}{lll}
\hline Infection model & Mutant CWA in S. aureus & Result \\
\hline Murine kidney abscess & Sortase & No abscess formation in the kidneys \\
Murine skin infection & ClfA & Decreased CFU in the skin abscess \\
Murine skin infection & FnBPA and FnBPB & Decreased CFU in the skin abscess \\
Murine skin infection & SasX & Smaller abscesses in the skin \\
Mice inoculated subcutaneously & Protein A & Decreased CFU in the skin abscesses \\
Rabbit skin infection & Wild-type & $\begin{array}{l}\text { High transcription level of the isdB } \\
\text { gene in abscesses }\end{array}$ \\
\hline
\end{tabular}

Table 2. CWA protein infection models.

strain of S. aureus, who produced smaller abscesses compared with those infected with the wildtype strain. In mice inoculated subcutaneously with the S. aureus Newman mutant strain, protein A-deficient, the bacterial load on the skin abscesses was significantly lower than abscesses infected the wild-type strain. The role of protein A during skin infection by S. aureus is probably by evading the immune response, since protein A binds to IgG and decrements B cells, prolonging the time of bacterial binding with the ligand of the skin. Protein A leads a proinflammatory response in the skin, because the protein A binds to TNFR1 of human keratinocytes and upregulates the expression of COX-2 and IL-8, driving shot downstream of the kinases, which results in the activation of NFkB and AP-1 [62]. IsdA has a function of resistance against the mechanisms of human innate immune defense and its presence on the surface of $S$. aureus causes that the bacterium to be more hydrophilic and is negatively charged [63,64]. In a rabbit skin infection model, transcription levels of is $d B$ were increased $24 \mathrm{~h}$ post infection [65], suggesting that it may have a role during infection of the skin. The Isd proteins bind to the ligands on skin cells, and it is probably Isd that is involved in the skin infection.

\section{CWA proteins as vaccines}

Currently, there is a proposal to use recombinant CWA proteins as potential vaccine antigens. In animal models, the use of CWA proteins has induced immunological protection against $S$. aureus through the production of anti-S. aureus antibody [66-68]. However, it has been documented that IsdB vaccine produced immunity in animals, but not in patients with severe infections after cardiothoracic surgery (phase III test) [69, 70]. A strategy to increase vaccine efficacy is to develop multiple vaccines, a vaccine containing four antigens of CWA proteins resulted in greater protection in mouse [68] compared to a single antigen vaccine. Furthermore, the stimulation of humoral immunity is insufficient for protection in humans; subsequently adjuvants that trigger an immune response mediated by T helper 1 (Th1) and/or T helper 17 (Th17) cells, as well as recruit of neutrophils by IL-17 and IFN $\gamma$ would be important.

\subsection{CWA proteins such as $\mathrm{T}$-cell antigen}

Up to date, the mechanism of immune system activation by CWA proteins is unknown except for the protein A that binds to TNFR1 and induces the production of interleukin-8 (IL-8) 
and the neutrophil recruitment [50]. The anti-S. aureus vaccines are capable for activating the effector T-cell subsets [71, 72]; however, the epitopes of $S$. aureus that recognize T-cells are unknown. T-cells not activated (virgin) increase their cellular proliferation and production of cytokines (phenotype of activated T-cells) when they are stimulated with extracellular proteins of $S$. aureus, but not when they are stimulated with intracellular proteins of $S$. aureus [73]. Stimulation of virgin T-cell with membrane proteins from S. aureus produces a high activation of T-cells, the same takes place when they are stimulated with ClfA [74]. ClfA triggers immunity antibody-mediated in a murine model of S. aureus arthritis [67]. On the other hand, ClfA nanoparticle applied to the nasal cavity of mice results in a significant protection against systemic infection by S. aureus, and an increase cellular immune response Th1 and Th17 [68]. Immune cellular response type Th17 has an important function in systemic protection against S. aureus, because knockout mice to IL-17 cytokine are not immunized with ClfA [75]. These studies suggest the potential role of ClfA as the major antigen to activate T-cells.

Currently, ClfA protein is used in multivalent vaccines. Thus, the vaccine designed by Pfizer, with the status of Phase II clinical trials, is made with ClfA antigens, capsular polysaccharide MNTC, and two proteins (CP5 and CP8) [76, 77]. This vaccine induces a high production of antibodies; however, there are no studies on its cellular immunity. NovaDigm I developed a vaccine with homologues of ClfA and Als3p [78]; in phase I clinical test, the vaccine showed an increase in the production of specific antibody titer and induced Th1 and Th17 cell response in humans [77]. ClfA is emerging as a potent stimulator of T-cells and it is a promising antigen vaccine development; however, there is little research on the potential of other CWA proteins to activate T-cells. Therefore, studies to determine which CWA proteins cause a high T-cell response should be performed to identify potential proteins for future vaccines.

\section{Conclusions}

Although it has recognized the role and ligands for some CWA proteins of S. aureus, there are other CWA proteins whose function in humans is unknown. The structural analysis of CWA proteins is a powerful tool to determine their role in S. aureus; however, the use of molecular techniques and animal models are essential for discovering new ligands and/or functions of the CWA proteins, which could be relevant in S. aureus pathogenicity.

On the other hand, the immune response of the CWA protein also requires more studies, since the mechanism by which CWA proteins interfere with the host innate immune response is unknown, in particular regulation of complement activation. In addition, determining CWA proteins causing a cellular immune response is crucial for the generation of new vaccines.

Most studies of CWA proteins have been conducted with laboratory strains. These studies should be extended in clinical isolates, where the variation of ligand binding of the CWA proteins is considerable. Additionally, the regulatory system of the expression of CWA proteins is still insufficient, because the expression of CWA proteins depends on the strain understudy.

Surface proteins have a wide range of functions that are essential for colonization and survival of S. aureus in the host. Although the structural analysis of the CWA proteins has been crucial to define the mechanism of these processes and has provided the classification of the 
CWA proteins, there are many questions to understand completely the functions of the CWA proteins in the pathogenesis of $S$. aureus.

\section{Acknowledgements}

This work was supported by the Grant SIP20160325, SIP20161111, and SIP20160135 from Instituto Politécnico Nacional (IPN). JCCD, JJR, SRM, and MECD appreciate the COFAA and EDI, IPN fellowships, and the support provided by SNI-CONACYT. EGG thanks the CONACYT Postdoctoral fellowship and the support provided by SNI-CONACYT.

\section{Author details}

Janet Jan-Roblero ${ }^{1}$, Elizabeth García-Gómez ${ }^{1}$, Sandra Rodríguez-Martínez², Mario E. CancinoDiaz $^{2}$ and Juan C. Cancino-Diaz ${ }^{1 *}$

*Address all correspondence to: jccancinodiaz@hotmail.com

1 Microbiology Department, ENCB, National Polytechnic Institute (Instituto Politécnico Nacional), Mexico City, Mexico

2 Inmunology Department, ENCB, National Polytechnic Institute (Instituto Politécnico Nacional), Mexico City, Mexico

\section{References}

[1] DeLeo FR, Chambers HF. Reemergence of antibiotic-resistant Staphylococcus aureus in the genomics era. Journal of Clinical Investigation. 2009;119:2464-2474. DOI: 10.1172/JCI38226

[2] DeLeo FR, Otto M, Kreiswirth BN, Chambers HF. Community-associated meticillin-resistant Staphylococcus aureus. Lancet. 2010;375:1557-1568. DOI: 10.1016/ S0140-6736(09)61999-1

[3] Mazmanian SK, Skaar EP, Gaspar AH, Humayun M, Gornicki P, Jelenska J, Joachmiak A, Missiakas DM, Schneewind O. Passage of heme-iron across the envelope of Staphylococcus aureus. Science. 2003;299:906-909. DOI: 10.1126/science.1081147

[4] Hammer ND, Skaar EP. Molecular mechanisms of Staphylococcus aureus iron acquisition. Annual Review of Microbiology. 2011;65:129-147. DOI: 10.1146/annurev-micro090110-102851

[5] McAleese FM, Walsh EJ, Sieprawska M, Potempa J, Foster TJ. Loss of clumping factor B fibrinogen binding activity by Staphylococcus aureus involves cessation of transcription, shedding and cleavage by metalloprotease. Journal of Biological Chemistry. 2001;276:29969-29978. DOI: 10.1074/jbc.M102389200 
[6] Bischoff M, Dunman P, Kormanec J, Macapagal D, Murphy E, Mounts W, Berger-Bächi B, Projan S. Microarray-based analysis of the Staphylococcus aureus sigma-B regulon. Journal of Bacteriology. 2004;186:4085-4099. DOI: 10.1128/JB.186.13.4085-4099.2004

[7] Deivanayagam CC, Wann ER, Chen W, Carson M, Rajashankar KR, Hook M, Narayana SV. A novel variant of the immunoglobulin fold in surface adhesins of Staphylococcus aureus: crystal structure of the fibrinogen-binding MSCRAMM, clumping factor A. EMBO Journal. 2002;21:6660-6672. DOI: 10.1093/emboj/cdf619

[8] Ponnuraj KA, Bowden MG, Davis S, Gurusiddappa S, Moore D, Choe D, Xu Y, Hook M, Narayana SV. A "dock, lock, and latch" structural model for a staphylococcal adhesin binding to fibrinogen. Cell. 2003;115:217-228. DOI: 10.1016/S0092-8674(03)00809-2

[9] Josefsson E, McCrea KW, Ni Eidhin D, O'Connell D, Cox J, Hook M, Foster TJ. Three new members of the serine-aspartate repeat protein multigene family of Staphylococcus aureus. Microbiology. 1998;144:3387-3395. DOI: 10.1099/00221287-144-12-3387

[10] Josefsson E, O'Connell D, Foster TJ, Durussel I, Cox JA. The binding of calcium to the B-repeat segment of SdrD, a cell surface protein of Staphylococcus aureus. Journal of Biological Chemistry. 1998;273:31145-31152. DOI: 10.1074/jbc.273.47.31145

[11] Cassat JE, Skaar EP. Metal ion acquisition in Staphylococcus aureus: overcoming nutritional immunity. Seminars in Immunopathology. 2012;34:215-235. DOI: 10.1007/s00281-011-0294-4

[12] Grigg JC, Ukpabi G, Gaudin CF, Murphy ME. Structural biology of heme binding in the Staphylococcus aureus Isd system. Journal of Inorganic Biochemistry. 2010;104:341-348. DOI: 10.1016/j.jinorgbio.2009.09.012

[13] Deisenhofer J. Crystallographic refinement and atomic models of a human Fc fragment and its complex with fragment B of protein A from Staphylococcus aureus at 2.9- and 2.8-A resolution. Biochemistry. 1981;20:2361-2370. DOI: 10.1021/bi00512a001

[14] Cedergren L, Andersson R, Jansson B, Uhlen M, Nilsson B. Mutational analysis of the interaction between staphylococcal protein A and human IgG1. Protein Engineering. 1993;6:441-448. DOI: 10.1093/protein/6.4.441

[15] Smith EJ, Corrigan RM, van der Sluis T, Gründling A, Speziale P, Geoghegan JA, Foster TJ. The immune evasion protein Sbi of Staphylococcus aureus occurs both extracellularly and anchored to the cell envelope by binding lipoteichoic acid. Molecular Microbiology. 2012;83:789-804. DOI: 10.1111/j.1365-2958.2011.07966.x

[16] Burman JD, Leung E, Atkins KL, O'Seaghdha MN, Lango L, Bernado P, Bagby S, Svergun DI, Foster TJ, Isenman DE, van den Elsen JM. Interaction of human complement with Sbi, a staphylococcal immunoglobulin-binding protein: indications of a novel mechanism of complement evasion by Staphylococcus aureus. Journal of Biological Chemistry. 2008;283:17579-17593. DOI: 10.1074/jbc.M800265200

[17] Lambris JD, Ricklin D, Geisbrecht BV. Complement evasion by human pathogens. Nature Reviews: Microbiology. 2008;6:132-142. DOI: 10.1038/nrmicro1824 
[18] Gruszka DT, Wojdyla JA, Bigham RJ, Turkenburg JP, Manfield IW, Steward A, Leech AP, Geoghegan JA, Foster TJ, Clarke J, Potts JR. Staphylococcal biofilm-forming protein has a contiguous rod-like structure. Proceedings of the National Academy of Sciences of the United States of America. 2012;109:E1011-E1018. DOI: 10.1073/pnas.1119456109

[19] Conrady DG, Wilson JJ, Herr AB. Structural basis for $\mathrm{Zn}^{2+}$-dependent intercellular adhesion in staphylococcal biofilms. Proceedings of the National Academy of Sciences of the United States of America. 2013;110:E202-E211. DOI: 10.1073/pnas.1208134110

[20] Geoghegan JA, Corrigan RM, Gruszka DT, Speziale P, O'Gara JP, Potts JR, Foster TJ. Role of surface protein SasG in biofilm formation by Staphylococcus aureus. Journal of Bacteriology. 2010;192:5663-5673. DOI: 10.1128/JB.00628-10

[21] Lizcano A, Sanchez CJ, Orihuela CJ. A role for glycosylated serine-rich repeat proteins in gram-positive bacterial pathogenesis. Molecular Oral Microbiology. 2012;27(4):257-269. DOI: $10.1111 /$ j.2041-1014.2012.00653.x

[22] Kukita K, Kawada-Matsuo M, Oho T, Nagatomo M, Oogai Y, Hashimoto M, Suda Y, Tanaka T, Komatsuzawa H. Staphylococcus aureus SasA. is responsible for binding to salivary agglutinin, gp340, derived from human saliva. Infection and Immunity. 2013;81:1870-1879. DOI: 10.1128/IAI.00011-13

[23] Thammavongsa V, Kern JW, Missiakas DM, Schneewind O. Staphylococcus aureus synthesizes adenosine to escape host immune responses. Journal of Experimental Medicine. 2009;206:2417-2427. DOI: 10.1084/jem.20090097

[24] Thammavongsa V, Schneewind O, Missiakas DM. Enzymatic properties of Staphylococcus aureus adenosine synthase (AdsA). BMC Biochemistry. 2011;12:56. DOI: 10.1186/1471-2091-12-56

[25] Berends ET, Horswill AR, Haste NM, Monestier M, Nizet V, von Kockritz-Blickwede M. Nuclease expression by Staphylococcus aureus facilitates escape from neutrophil extracellular traps. Journal of Innate Immunity. 2010;2(6):576-586. DOI: 10.1159/000319909

[26] Thammavongsa V, Missiakas DM, Schneewind O. Staphylococcus aureus degrades neutrophil extracellular traps to promote immune cell death. Science. 2013;342(6160):863866. DOI: $10.1126 /$ science. 1242255

[27] Geoghegan JA, Monk IR, O'Gara JP, Foster TJ. Subdomains N2N3 of fibronectin binding protein A mediate Staphylococcus aureus biofilm formation and adherence to fibrinogen using distinct mechanisms. Journal of Bacteriology. 2013;195:2675-2683. DOI: 10.1128/ JB.02128-12

[28] McCormack N, Foster TJ, Geoghegan JA. A short sequence within subdomain N1 of region A of the Staphylococcus aureus MSCRAMM clumping factor A is required for export and surface display. Microbiology. 2014;160(Pt 4):659-670. DOI: 10.1099/mic.0.074724-0

[29] McGavin MJ, Zahradka C, Rice K, Scott JE. Modification of the Staphylococcus aureus fibronectin binding phenotype by V8 protease. Infection and Immunity. 1997;65(7):2621-2628. 
[30] Hazenbos WL, Kajihara KK, Vandlen R, MorisakiJH, Lehar SM, Kwakkenbos MJ, Beaumont T, Bakker AQ, Phung Q, Swem LR, Ramakrishnan S, Kim J, Xu M, Shah IM, Diep BA, Sai T, Sebrell A, Khalfin Y, Oh A, Koth C, Lin SJ, Lee BC, Strandh M, Koefoed K, Andersen PS, Spits H, Brown EJ, Tan MW, Mariathasan S. Novel staphylococcal glycosyltransferases SdgA and SdgB mediate immunogenicity and protection of virulence-associated cell wall proteins. PLoS Pathogens. 2013;9(10):e1003653. DOI: 10.1371/journal.ppat.1003653

[31] Foster TJ, Geoghegan JA, Ganesh VK, Hook M. Adhesion, invasion and evasion: the many functions of the surface proteins of Staphylococcus aureus. Nature Reviews: Microbiology. 2014;12(1):49-62. DOI: 10.1038/nrmicro3161

[32] Kluytmans J, van Belkum A, Verbrugh H. Nasal carriage of Staphylococcus aureus: epidemiology, underlying mechanisms, and associated risks. Clinical Microbiology Reviews. 1997;10:505-520.

[33] Burian M, Rautenberg M, Kohler T, Fritz M, Krismer B, Unger C, Hoffmann WH, Peschel A, Wolz C, Goerke C. Temporal expression of adhesion factors and activity of global regulators during establishment of Staphylococcus aureus nasal colonization. Journal of Infectious Diseases. 2010;201:1414-1421. DOI: 10.1086/651619

[34] Schaffer AC, M. SR, Cocchiaro J, Portoles M, Kiser KB, Risley A, Randall SM, Valtulina V, Speziale P, Walsh E, Foster T, Lee JC. Immunization with Staphylococcus aureus clumping factor B, a major determinant in nasal carriage, reduces nasal colonization in a murine model. Infection and Immunity. 2006;74:2145-2153. DOI: 10.1128/IAI.74.4.2145-2153.2006

[35] Clarke SR, Brummell KJ, Horsburgh MJ, McDowell PW, Mohamad SA, Stapleton MR, Acevedo J, Read RC, Day NP, Peacock SJ, Mond JJ, Kokai-Kun JF, Foster SJ. Identification of in vivo-expressed antigens of Staphylococcus aureus and their use in vaccinations for protection against nasal carriage. Journal of Infectious Diseases. 2006;193:1098-1108. DOI: $10.1086 / 501471$

[36] Wertheim HF, Walsh E, Choudhurry R, Melles DC, Boelens HA, Miajlovic H, Verbrugh HA, Foster T, van Belkum A. Key role for clumping factor B in Staphylococcus aureus nasal colonization of humans. PLoS Medicine. 2008;5:e17. DOI: 10.1371/journal.pmed.0050017

[37] Walsh EJ, O'Brien LM, Liang X, Hook M, Foster TJ. Clumping factor B, a fibrinogenbinding MSCRAMM (microbial surface components recognizing adhesive matrix molecules) adhesin of Staphylococcus aureus, also binds to the tail region of type I cytokeratin 10. Journal of Biological Chemistry. 2004;279:50691-50699. DOI: 10.1074/jbc.M408713200

[38] Mulcahy ME, Geoghegan JA, Monk IR, O'Keeffe KM, Walsh EJ, Foster TJ, McLoughlin RM. Nasal colonisation by Staphylococcus aureus depends upon clumping factor B binding to the squamous epithelial cell envelope protein loricrin. PLoS Pathogens. 2012;8:e1003092. DOI: 10.1371/journal.ppat.1003092

[39] Corrigan RM, Rigby D, Handley P, Foster TJ. The role of Staphylococcus aureus surface protein SasG in adherence and biofilm formation. Microbiology. 2007;153:2435-2446. DOI: $10.1099 /$ mic.0.2007/006676-0 
[40] Corrigan RM, Miajlovic H, Foster TJ. Surface proteins that promote adherence of Staphylococcus aureus to human desquamated nasal epithelial cells. BMC Microbiology. 2009;9:22. DOI: 10.1186/1471-2180-9-22

[41] Li M, Du X, Villaruz AE, Diep BA, Wang D, Song Y, Tian Y, Hu J, Yu F, Lu Y, Otto M. MRSA epidemic linked to a quickly spreading colonization and virulence determinant. Nature Medicine. 2012;18:816-819. DOI: 10.1038/nm.2692

[42] Liu Q, Du X, Hong X, Li T, Zheng B, He L, Wang Y, Otto M, Li M. Targeting surface protein SasX by active and passive vaccination to reduce Staphylococcus aureus colonization and infection. Infection and Immunity. 2015;83(5):2168-2174. DOI: 10.1128/IAI.02951-14

[43] Sendi P, Proctor RA. Staphylococcus aureus as an intracellular pathogen: the role of small colony variants. Trends in Microbiology. 2009;17:54-58. DOI: 10.1016/j.tim.2008.11.004

[44] Dziewanowska K, Patti JM, Deobald CF, Bayles KW, Trumble WR, Bohach GA. Fibronectin binding protein and host cell tyrosine kinase are required for internalization of Staphylococcus aureus by epithelial cells. Infection and Immunity. 1999;67:4673-4678.

[45] Peacock SJ, Foster TJ, Cameron BJ, Berendt AR. Bacterial fibronectin-binding proteins and endothelial cell surface fibronectin mediate adherence of Staphylococcus aureus to resting human endothelial cells. Microbiology. 1999;145:3477-3486. DOI: $10.1099 / 00221287-145-12-3477$

[46] Sinha B, Francois PP, Nüsse O, Foti M, Hartford OM, Vandaux P, Foster TJ, Lew DP, Herrmann M, Krause KH. Fibronectin-binding protein acts as Staphylococcus aureus invasin via fibronectin bridging to integrin alpha5beta1. Cellular Microbiology. 1999;1:101117. DOI: 10.1046/j.1462-5822.1999.00011.x

[47] Schwarz-Linek U, Werner JM, Pickford AR, Gurusiddappa S, Him JH, Pilka ES, Briggs JA, Gough TS, Hook M, Campbell ID, Potts JR. Pathogenic bacteria attach to human fibronectin through a tandem beta-zipper. Nature. 2003;423:177-181. DOI: 10.1038/ nature01589

[48] Schwarz-Linek U, Hook M, Potts JR. Fibronectin-binding proteins of Gram-positive cocci. Microbes and Infection. 2006;8:2291-2298. DOI: 10.1016/j.micinf.2006.03.011

[49] Smith EJ, Visai L, Kerrigan SW, Speziale P, Foster TJ. The Sbi protein is a multifunctional immune evasion factor of Staphylococcus aureus. Infection and Immunity. 2011;79:38013809. DOI: 10.1128/IAI.05075-11

[50] Gomez MI, Lee A, Reddy B, Muir A, Soong G, Pitt A, Cheung A, Prince A. Staphylococcus aureus protein $\mathrm{A}$ induces airway epithelial inflammatory responses by activating TNFR1. Nature Medicine. 2004;10:842-848. DOI: 10.1038/nm1079

[51] Martin FJ, Gomez MI, Wetzel DM, Memmi G, O'Seaghdha MN, Soong G, Schindler C, Prince A. Staphylococcus aureus activates type I IFN signaling in mice and humans through the $\mathrm{Xr}$ repeated sequences of protein A. Journal of Clinical Investigation. 2009;119:1931-1939. DOI: 10.1172/JCI35879 
[52] Hair PS, Ward MD, Semmes OJ, Foster TJ, Cunnion KM. Staphylococcus aureus clumping factor A binds to complement regulator factor I and increases factor I cleavage of C3b. Journal of Infectious Diseases. 2008;198:125-133. DOI: 10.1086/588825

[53] Flick MJ, Du X, Prasad JM, Raghu H, Palumbo JS, Smeds EH, M., Degen JL. Genetic elimination of the binding motif on fibrinogen for the $S$. aureus virulence factor ClfA improves host survival in septicemia. Blood. 2013;121:1783-1794. DOI: 10.1182/blood-2012-09-453894

[54] Rohde H, Knobloch JK, Horstkotte MA, Mack D. Correlation of Staphylococcus aureus icaADBC genotype and biofilm expression phenotype. Journal of Clinical Microbiology. 2001;39(12):4595-4596. DOI: 10.1128/JCM.39.12.4595-4596.2001

[55] Otto M. Staphylococcus epidermidisthe 'accidental' pathogen. Nature Reviews: Microbiology. 2009;7(8):555-567. DOI: 10.1038/nrmicro2182

[56] Cucarella C, Solano C, Valle J, Amorena B, Lasa I, Penades JR. Bap, a Staphylococcus aureus surface protein involved in biofilm formation. Journal of Bacteriology. 2001;183:28882896. DOI: 10.1128/JB.183.9.2888-2896.2001

[57] Schroeder K, Jularic M, Horsburgh SM, Hirschhausen N, Neumann C, Bertling A, Schulte A, Foster S, Kehrel BE, Peters G, Heilmann C. Molecular characterization of a novel Staphylococcus aureus surface protein (SasC) involved in cell aggregation and biofilm accumulation. PloS One. 2009;4:e7567. DOI: 10.1371/journal.pone.0007567

[58] Mazmanian SK, Liu G, Jensen ER, Lenoy E, Schneewind O. Staphylococcus aureus sortase mutants defective in the display of surface proteins and in the pathogenesis of animal infections. Proceedings of the National Academy of Sciences of the United States of America. 2000;97(10):5510-5515. DOI: 10.1073/pnas.080520697

[59] Cheng AG, Kim HK, Burts ML, Krausz T, Schneewind O, Missiakas DM. Genetic requirements for Staphylococcus aureus abscess formation and persistence in host tissues. FASEB Journal. 2009;23:3393-3404. DOI: 10.1096/fj.09-135467

[60] Kwiecinski J, Jin T, Josefsson E. Surface proteins of Staphylococcus aureus play an important role in experimental skin infection. Acta Pathologica, Microbiologica et Immunologica Scandinavica. 2014;122(12):1240-1250. DOI: 10.1111/apm.12295

[61] Edwards AM, Potter U, Meenan NA, Potts JR, Massey RC. Staphylococcus aureus keratinocyte invasion is dependent upon multiple high-affinity fibronectin-binding repeats within FnBPA. PloS One. 2011;6(4):e18899. DOI: 10.1371/journal.pone.0018899

[62] Classen A, Kalali BN, Schnopp C, Andres C, Aguilar-Pimentel JA, Ring J, Ollert M, Mempel $\mathrm{M}$. TNF receptor I on human keratinocytes is a binding partner for staphylococcal protein A resulting in the activation of NF kappa B, AP-1, and downstream gene transcription. Experimental Dermatology. 2011;20(1):48-52. DOI: 10.1111/j.1600-0625.2010.01174.x

[63] Clarke SR, Mohamed R, Bian L, Routh AF, Kokai-Kun JF, Mond JJ, Tarkowski A, Foster SJ. The Staphylococcus aureus surface protein IsdA mediates resistance to innate defenses of human skin. Cell Host Microbe. 2007;1:199-212. DOI: 10.1016/j.chom.2007.04.005 
[64] Clarke SR, Foster SJ. IsdA protects Staphylococcus aureus against the bactericidal protease activity of apolactoferrin. Infection and Immunity. 2008;76:1518-1526. DOI: 10.1128/ IAI.01530-07

[65] Malachowa N, Kobayashi SD, Sturdevant DE, Scott DP, DeLeo FR. Insights into the Staphylococcus aureus-host interface: global changes in host and pathogen gene expression in a rabbit skin infection model. PloS One. 2015;10(2):e0117713. DOI: 10.1371/journal.pone. 0117713

[66] Nilsson IM, Patti JM, Bremell T, Hook M, Tarkowski A. Vaccination with a recombinant fragment of collagen adhesin provides protection against Staphylococcus aureus-mediated septic death. Journal of Clinical Investigation. 1998;101:2640-2649. DOI: 10.1172/JCI1823

[67] Josefsson E, Hartford O, O'Brien L, Patti JM, Foster T. Protection against experimental Staphylococcus aureus arthritis by vaccination with clumping factor A, a novel virulence determinant. Journal of Infectious Diseases. 2001;184:1572-1580. DOI: 10.1086/324430

[68] Stranger-Jones YK, Bae T, Schneewind O. Vaccine assembly from surface proteins of Staphylococcus aureus. Proceedings of the National Academy of Sciences of the United States of America. 2006;103:16942-16947. DOI: 10.1073/pnas.0606863103

[69] Bagnoli F, Bertholet S, Grandi G. Inferring reasons for the failure of Staphylococcus aureus vaccines in clinical trials. Frontiers in Cellular and Infection Microbiology. 2012;2:16. DOI: $10.3389 /$ fcimb.2012.00016

[70] Fowler VG, Allen KB, Moreira ED, Moustafa M, Isgro F, Boucher HW, Corey GR, Carmeli Y, Betts R, Hartzel JS, Chan IS, McNeely TB, Kartsonis NA, Guris D, Onorato MT, Smugar SS, DiNubile MJ, Sobanjo-ter Meulen A. Effect of an investigational vaccine for preventing Staphylococcus aureus infections after cardiothoracic surgery: a randomized trial. The Journal of the American Medical Association. 2013;309:1368-1378. DOI: 10.1001/jama.2013.3010

[71] Spellberg B, Ibrahim AS, Yeaman MR, Lin L, Fu Y, Avanesian V, Bayer AS, Filler SG, Lipke $\mathrm{P}$, Otoo $\mathrm{H}$, Edwards JE, Jr. The antifungal vaccine derived from the recombinant $\mathrm{N}$ terminus of Als3p protects mice against the bacterium Staphylococcus aureus. Infection and Immunity. 2008;76(10):4574-4580. DOI: 10.1128/IAI.00700-08

[72] Misstear K, McNeela EA, Murphy AG, Geoghegan JA, O'Keeffe KM, Fox J, Chan K, Heuking S, Collin N, Foster TJ, McLoughlin RM, Lavelle EC. Targeted nasal vaccination provides antibody-independent protection against Staphylococcus aureus. Journal of Infectious Diseases. 2014;209(9):1479-1484. DOI: 10.1093/infdis/jit636

[73] Kolata JB, Kuhbandner I, Link C, Normann N, Vu CH, Steil L, Weidenmaier C, Broker BM. The Fall of a Dogma? Unexpected High T-Cell Memory Response to Staphylococcus aureus in Humans. Journal of Infectious Diseases. 2015;212(5):830-838. DOI: 10.1093/ infdis/jiv128jo

[74] Fowler VG, Jr., Proctor RA. Where does a Staphylococcus aureus vaccine stand? Clinical Microbiology and Infection. 2014;20 Suppl 5:66-75. DOI: 10.1111/1469-0691.12570 
[75] Narita K, Hu DL, Mori F, Wakabayashi K, Iwakura Y, Nakane A. Role of interleukin-17A in cell-mediated protection against Staphylococcus aureus infection in mice immunized with the fibrinogen-binding domain of clumping factor A. Infection and Immunity. 2010;78(10):4234-4242. DOI: 10.1128/IAI.00447-10

[76] Nissen M, Marshall H, Richmond P, Shakib S, Jiang Q, Cooper D, Rill D, Baber J, Eiden J, Gruber W, Jansen KU, Emini EA, Anderson AS, Zito ET, Girgenti D. A randomized phase I study of the safety and immunogenicity of three ascending dose levels of a 3-antigen Staphylococcus aureus vaccine (SA3Ag) in healthy adults. Vaccine. 2015;33(15):1846-1854. DOI: 10.1016/j.vaccine.2015.02.024

[77] Proctor RA. Recent developments for Staphylococcus aureus vaccines: clinical and basic science challenges. European Cells and Materials. 2015;30:315-326.

[78] SchmidtCS, White CJ, Ibrahim AS, Filler SG, Fu Y, Yeaman MR, Edwards JE, Jr., Hennessey JP, Jr. NDV-3, a recombinant alum-adjuvanted vaccine for Candida and Staphylococcus aureus, is safe and immunogenic in healthy adults. Vaccine. 2012;30(52):7594-7600. DOI: 10.1016/j.vaccine.2012.10.038 
